\title{
RECOGNIZING EARLY WARNING SIGNS IN TRANSPORTATION SERVICES
}

\section{IWONA PISZ}

Opole University, POLAND

e-mail: ipisz@uni.opole.pl

\author{
RECEIVED \\ 9 August 2017 \\ ACCEPTED \\ 15 December 2017 \\ JEL \\ CLASSIFICATION \\ L20, L80, L91
}

KEYWORDS

transport, service, oversize cargo, early warning, project, logistics project

ABSTRACT

The transport services can vary in complexity, and can be carried out in short or long supply chains. Market observations indicate that logistics services including transport service become increasingly sophisticated, by far exceeding their traditional perception. They begin to resemble projects characterized by singularity, uniqueness, temporariness, limited budget, and, occasionally, innovativeness. Therefore, they are often treated as a specific type of projects, called logistics projects. The aim of the paper is to present the essence and characteristics of transportation services as a specific logistics project. Author characterizes the transportation service, with particular focus on the sector of oversized cargo transportation. The demand for such services depends on the industry, energy, infrastructure development, investment projects in particular countries as well as on economic policies. Transportation of non-standard cargos creates non-standard problems. The management of such services requires specific knowledge, resources, and managers. The paper identifies key factors that need to be taken under consideration when planning oversized cargo transportation services, i.e. early warning signs. The author presents certain barriers to responding to early warning signs in oversize transport service.

\section{Introduction}

An early warning sign is an observation, a signal, a message, or some other form of communication. It is or can be seen as expression, indication, proof, or sign of the existence of some future or incipient positive or negative issue. Early warning signs are signals, omens, or indications of future developments (Nikander, 2002). These signs are possible to identify in organizations (Haji-kazemi, 2015; Williams, Klakegg, Walker, Andersen, Magnussen, 
2012). It is possible to detect early warning signs in projects including logistics project undertaken by organizations and by supply chains. Recognizing early warning signs is an integrated element in project management practices. The research reviews (Williams et al., 2012) shows that project professionals are not good at detecting or acting on early warning signs. Williams and his research team (2012) have found little evidence that project managers have found ways to exploit early warning signs to identify and deflect future problems, the appropriate responses on early warning signs in projects are missing from project managers in many cases.

The basic service on the logistics market, arising out of the need for moving various goods from their collection point to their destination, is transportation. Transportation services are an integral part of logistics systems. Transportation services are very important in the world. They are a basic element of logistics services. These kind of services comprise all relevant interdependencies between production, transfer, and consumption and are integrated into the value chains of senders and receivers (Gleissner, Femerling, 2013). Transportation services are provided by many companies with a various scope of offers, knowledge, experience, teams, equipment, scope of operation and size. Both large and small companies function on this market, companies providing diversified services, starting from a typical transport service, through shipping, storage, packaging and customizing, packing, to a complex service for entire supply chains on the domestic and international scale (Wiktorowska-Jasik, 2016). Oversize transport is a special one of these services. This kind of service is the application of limited resources, competences including knowledge and skills by one entity for the benefit of another. Management of such services is similar to project management. Oversized transportation can be treated as a specific project called logistics project. Logistics project is a non-routine set of task apart from other projects by time and cost, the purpose of which is to perform a singular, and unique action that effects change to the logistics system of a one enterprise or a supply chain within which this enterprise operates (Pisz, Łapuńka, 2016).

The purpose of the paper is to analyze the oversized transportation services in terms of the complexity. The particular attention was paid to the early warning concept in such orders. The paper presents the impact of recognizing early warning signs on the project's success. The similarity of transportation services to logistics projects was depicted. Barriers to early warning signs in oversize transport service were presented based on literature review and studies in three companies of oversize transport.

\section{Oversized transportation services}

The world needs innovative transportation services. Logistics operations, in which transport services are included should be sustainability. Economic practice shows that large third-party logistics (3PL) providers have usually environmental sustainability goals (Lieb, Lieb, 2010). From the other hand new technologies in communication and robotics have a substantial influence on transportation (Fries, Chowdhury, Brummond, 2009). These technologies have given rise to the prospect of autonomous vehicle (AV) technology which aims to reduce crashes, energy consumption, transportation cost, pollution, and congestion while at the same time increasing transport accessibility (Bagloee, Tavana, Asadi, Oliver, 2016).

Transportation services cause movements of people or goods. The market of transport services is a complex structure whose efficiency of operation depends on the integration of systems: physical movement, information flow, payments and general conditions for concluding transactions (Wiktorowska-Jasik, 2016). We can distinguish between internal and external transportation services. Internal transportation services, for instance, occur within a plant among different departments of a warehouse. External ones take place between suppliers and customers or 
between plants and warehouses. Companies use their own vehicles (private haulage) or logistics service providers to carry out transport services (Gleissner, Femerling, 2013).

One kind of transportation service is oversize transport. These kind of service is dedicated to movements of oversized goods (Figure 1). Oversize transport is usually a very important part of every development project, including infrastructure projects, construction projects, production projects, etc. Oversized transportation is a big part of industry, energy, infrastructure development (Gabor et al., 2011).

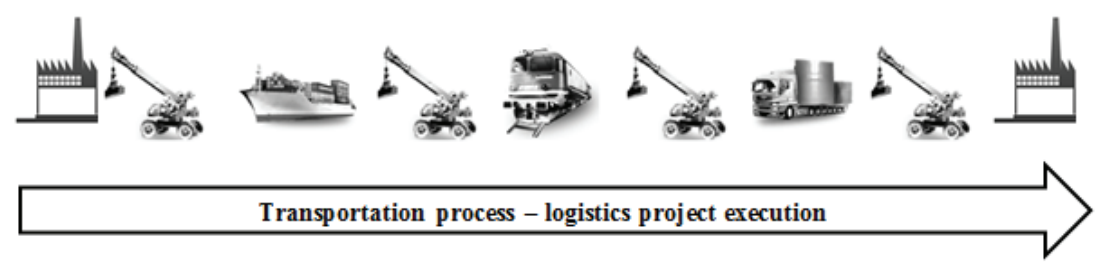

Figure 1. An example of oversize transport service execution

Source: own elaboration.

Oversize transport is a special one of service type. This kind of service is the application of limited resources, competences including knowledge and skills by one entity for the benefit of another. Oversized transportation is a unique subset of transportation services. These kind of services span the boundaries between suppliers and customers and have become increasingly important to successful supply chain operations. These sets of activities is very essence of many business. Oversize transport services can vary in complexity, and can be carried out in a company (production company) or in a supply chain. Market observations indicate that these kind of services become increasingly sophisticated, by far exceeding their traditional perception. It significantly affects the economic development of each country, where, however, various regulations and solutions are in use (Gabor et al., 2011; Pisz, Łapuńka, 2016). Oversize transport begin to resemble projects characterized by singularity, uniqueness, temporariness, limited budget, and, occasionally, innovativeness. The majority of orders received by logistics service providers constitute separate and singular transportation processes, which necessitate detailed analysis, planning as well as appropriate management methods. Therefore, they are often treated as a specific type of projects, called logistics projects. In order to fulfill the order it requires dedicated, and thus costly equipment. It must be emphasized that in the case of mass transportation, a range of ready-made semitrailers can be readily purchased, whereas in the case of non-standard transportation - these must be ordered beforehand (e.g., in road transportation - multiaxis modules are typically ordered approximately two years in advance). Entrepreneurs specializing in oversized cargo transportation are required to anticipate future market situation as well as the directions of economic development. For instance, a particular enterprise must assess whether or not it requires multi-axis semitrailers and to what kind of cargo will they be dedicated - low or high, long or extendable, perhaps heavy, etc. Transportation company undertaken these kind of project is expected to be able to suitably configure the vehicle and the semitrailer designed for the transportation of such cargos, since there is no single applicable standard. Such a configuration is particular to a given transportation order. Non-standard cargo transportation is carried out with suitably fitted vehicles, the carrying capacity, structure, and labeling of which are usually different from those of standard means 
of transportation. In order to organize the transit of such vehicles, appropriate permits are required, as well as advance arrangements with appropriate infrastructure administrators. This involves obtaining specific permits and decisions of authorized entities. The non-standard cargo creates non-standard problems. Transportation these kind of load is executed under risk and uncertainty. This includes transportation of special loads (abnormal loads, oversized cargo), which can be considered highly problematic and therefore requires special care. The process of its management is similar to project management, especially logistics project management.

Carrying out a logistics service in the context of oversized cargo transportation displays features of a logistics project. It constitutes a group of diverse activities, the aim of which is to meet requirements in terms of time, cost and scope. Oversized cargo transportation is the final element in a long chain of specialist logistics operations. It requires an appropriate approach, the use of suitable methods and equipment. From the perspective of an employer, i.e., an entrepreneur responsible for delivering oversized cargo, an order to deliver such cargo is a unique undertaking, which requires an individual approach. This necessitates an assessment of the market of oversized cargo transportation, selecting a logistics operator based on the chosen assessment criteria, and commissioning the organization and execution of oversized cargo transportation. In order to carry out such a logistics service, a contractor, i.e., a logistics operator, must prepare thoroughly, must possess or rent appropriate equipment, as well as demonstrate knowledge and experience in this type of transportation. It is essential to determine the feasibility of transportation, analyze all possible means of transportation, and choose the optimal one, and to assess and select loading and unloading equipment. Moreover, it is necessary to analyze available means of transportation and all permissible routes of oversized cargo transportation, and to select the optimal route. A logistics operator should make plans for loading, unloading and securing individual elements of the cargo, and determine the possible approaches for protecting the cargo against external conditions.

\section{Early warning signs in oversized transportation projects}

An important challenge in planning, execution and control of the undertaken logistics project like oversize transport in intra- and cross-company in supply chains is the capability to react to unforeseen deviations and disruptions. Oversize transport is the last link of a long chain of specialized logistic operations. The service providers have to make careful preparations, provide for proper equipment and have right experience in oversize cargo carriage. For the entire operation to be successful, the appropriate routes have to be selected along with the right vehicles, and the plan for loading and securing each oversize cargos have to be drawn up. Vehicles adjusted to carry oversize cargo generally have the dimensions; load capacity, design and marking that differ from standard vehicles. Cargo handling equipment has much higher lifting capacity than cranes or other machines handling standard items.

Besides, to arrange a smooth movement of the oversize cargo carrying vehicle, one needs special permits and other arrangements with transport infrastructure managers concerning the route, and, naturally, cargo has to be insured. If the transport is international, the operator has to satisfy the requirements of the region to be crossed, which sometimes is very difficult.

The basic functionality of early warning systems consists of detecting the event and quickly warning the users. Early warning system as a tool is concerned with looking into the future of the process or project which is always uncertain, and discussing what it might mean for decision-making in the present or in the future (Haji-Kazemi, 2015). The ability to react in real-time to hazards and disturbances, especially within time-critical processes, becomes 
more and more important for many enterprises and supply chain (Genca, Duffieb, Reinharta, 2014; Wieland, Wallenburg, 2013).

In this context the availability of real-time data concerning current events in the logistics and supply chain of logistics project execution is essential. Therefore research in the field of early warning system of projects including logistics project management is becoming more and more important. By being alert to the early warning signs, corrective actions can be taken in sufficient time to avoid adverse safety consequences. Companies must pay attention to sign of potential weaknesses (Weintrit, Neumann, 2013). Therefore the early warning signs should be identify in this kind of logistics project, in project life cycle, at decision gates/other milestones. We should note that the front end phase is an effective time to look for early warning signs in all projects, including oversize transportation. Roots of problems in later project phases of project life cycle are found in processes and decisions at the front-end of projects. During front end phase and especially during project execution phase some of warning signs can be omitted. It can be results of intense and distracting activity of project. We can observe that the original warning signals may have been conveniently ignored or intentionally hidden by project team and stakeholders. From other side some actions may be too late to avert when the warning signals are recognized.

Project assessment as a typically part of gateways is a useful tool in identifying early warning signals of the project. The ability to reflect on what happens (good and bad) in undertaken project is crucial for stakeholders including: sponsors, owner, project managers, team members, and assessors. Post-project lessons learned can be used to identify early warning signs. The reports should contain information about problems experienced that could be used for early warnings in the new project in the future. We should note that converting lessons learned/postproject reviews into either specific checklists of possible problems or more open lists of possible areas of concern can provide new projects with direct sources of early warning system (Williams, 2007). Postmortem analyses of unsuccessful projects are also good source for early warning signs. Postmortem analyses are generally conducted at the end of the project process, but are also useful at the end of each stage of a multi-phase project. The feedback gathered from project postmortem will be used to improve the management of future projects and should be used for building knowledge about final failure. These kind of analyses gives the project team a chance for calm reflection of the overall undertaken project, to talk about what went well and what could be done better next time in future projects. Figure 2 illustrates the main sources early warning signs detected by many persons and organizations and associations being part of a given projects - oversized transportation projects. The signals are detected based on project practice and the project environments. The information came from many sources. The signs are visible and invisible. The early warning signs are detected based on systematic use of project management tools and techniques and on project stakeholders' gut feelings.

Traditionally, time, cost, scope and quality are most highly rated as measures of project success (Klakegg, Williams, Walker, Andersen, Magnussen, 2010). Many researchers and practitioners consider success, performance and effectiveness as synonyms (Belout, 1998). It can be treated as the degree to which objectives are achieved (Baccarini, 1999; Belout, 1998). Success is corresponding to the effectiveness and the efficiency of the project and Brudney and England claim that efficiency is broadly understood as the maximization of output for a given level of input or resources. Various aspects of success were assessed: project efficiency (measured by the project management triangle), the project's impact on the client (measured by client satisfaction level), organization success (measured by the actual impact of project outcomes on the organization), as well as future-proofing (measuring how well project outcomes were aligned with the strategic goals of a company) (Mir, Pinnington, 2014). 


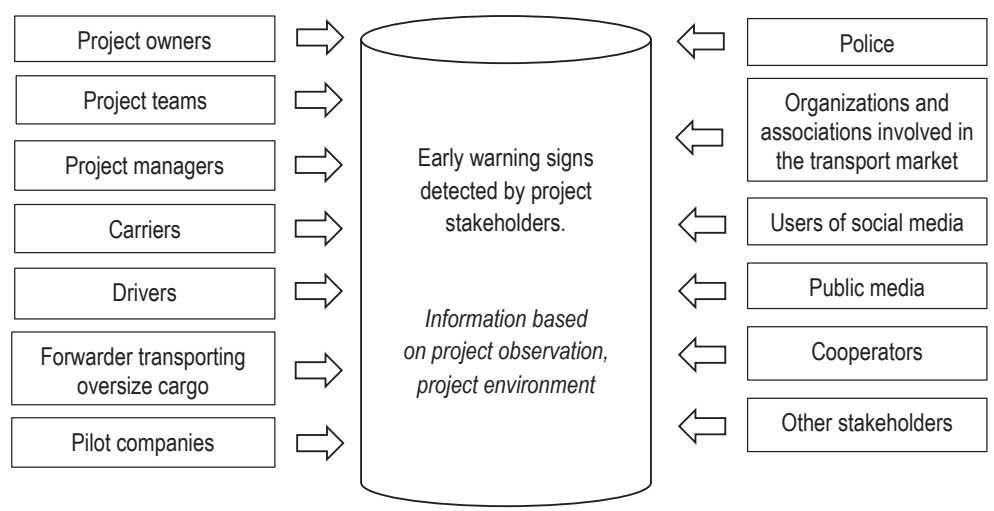

good damage road accident improper distribution of cargo loads capsizing of the vehicle bad weather conditions
closed roads fuel stealing goods stealing cost over budget delays of handling operations conflicts in project
teams stakeholder's bad feeling bad situation of cooperators strikes behind load schedule lost transportation
documentation lost permits traffic jams incorrect communication vehicle breakdown computer system failures
bad reputation of carriers bad behavior of drivers

Figure 2. Early warning signs detected in oversized transportation projects

Source: own elaboration.

Project success factors are consequences of many undertaken activities under risk and uncertainty, incidents, and other conscious or unconscious actions, or even lack of actions (Meyer, 2016). For the purpose of early warning in projects, there must be additional measures that can be provide relevant information. Project success is much more than simply success in these dimensions (Klakegg et al., 2010). Nevertheless, to date success has in principle been measured by business results. Today, we can note an evolution of project success concepts.

\section{Barriers to responding to early warning signs in oversize transport projects}

It is very important to known possible barriers to responding to early warning signs in projects of oversize transport. Based on the literature review and research findings, the author depicts certain possible barriers to the detection of early warning signs in projects including oversize transport projects. The available literature regarding the identification of possible sources of EW signs within projects has been examined in sources: (Bartsch, Ebers, Maurer, 2013; Flyvbjerg, Holm, Buhl, 2002; Flyvbjerg, Rothengatter, Bruzelius, 2003; Flyvbjerg, Garbuio, Lovallo, 2009; Hofstede, 1984; Klakegg et al., 2010; Lovallo, Kahneman, 2003; Williams et al., 2012).

The practice study has been carried out by the author based on form of interview. Project managers in three companies - specialist of transportation services were asked to depict the barriers to responding to early warning signs in transportation orders treated as logistics projects. Project managers and project teams usually make decisions based on own knowledge rather than on a rational weighting of gains, losses, and probabilities. Because of limit time they are forced to make fast decision. We can find some difficulties for acting due to lack of time to think ahead and question assumptions - the orders are limited by the schedule. The undertaken transport projects are usually very complexity. Interviewers pointed out that logistics project like oversize transport services are characterized by a high level of complexity, both in technical and organizational terms. The services are executed with cooperation with another companies (companies specialized in escorting heavy transport, permits, 
loading, etc.) and institutions (transport ministries, police, etc.). The data needed for decision making are imprecise, not crisp. Project situation is involved with flux and unpredictability and large amount of unknown unknowns. Because of large optimism of project team and project managers and owner of logistics providers usually cost are underestimated, benefits are overestimated, the potential for problems and miscalculations are overlooked. We can observe that project teams take their experience to the next project and fail to recognize the need to secure the ability of an organization to learn. The interviewed managers did not prepare right analysis of lessons learned. Form the other hand the project managers belief that the project assessments would capture all problems. Transportation services treated as logistics project are executed by projects team. The success of project is in their hands. They usually work in trust conditions. From the other hand the trust atmosphere can provide to hide the bad habits and practices. The drivers can steal fuel, the pilots can added kilometers, etc. It creates unreasonable costs of the project. The literature review and interviews show that sometime we can observe political pressure exerted by the project owners to implement a given solution. The interviewers underline that organization complexity can be one of barrier to responding to early warning signs in transportation orders.

\section{Conclusions}

The paper treated about early warning signs in specific transport services which are similar to unique type of projects. Orders for oversized transportation can be treated as specific projects named logistics projects. Transportation services such like oversize cargo transport are crucial to develop such sectors as industry, power supply or infrastructure. They make up an important part in any major investment project in companies and in supply chains.

Particular attention was paid to sources of early warning sing detected by stakeholders projects of oversize transport. The main actors of early warning signs were presented. The examples of early warning signals were shown. Additionally the main barriers to responding to early warning signs in projects of oversized transportation were presented on based on survey. The survey was executed in a chosen oversized transportation companies.

\section{References}

Bagloee, S.A., Tavana, M., Asadi, M., Oliver T. (2016). Autonomous vehicles: challenges, opportunities, and future implications for transportation policies. Journal of Modern Transportation, 4 (24), 284-303.

Baccarini, D. (1999). The logical framework method for defining project success. Project Management Journal, 4 (30), $25-32$.

Bartsch, V., Ebers, M., Maurer, I. (2013). Learning in project-based organizations: The role of project teams' social capital for overcoming barriers to learning. International Journal of Project Management, 31, 239-251.

Belout, A. (1998). Effects of human resource management on project effectiveness and success, toward a new conceptual framework. International Journal of Project Management, 1 (16), 21-26.

Flyvbjerg, B., Holm, M.S., Buhl, S. (2002). Underestimating costs in public works projects: Error or lie? Journal of the American Planning Association, 3 (68), 279-295.

Flyvbjerg, B., Rothengatter, W., Bruzelius, N. (2003). Megaprojects and risk: An anatomy of ambition. New York, NY: Cambridge University Press.

Flyvbjerg, B., Garbuio, M., Lovallo, D. (2009). Delusion and deception in large infrastructure projects: Two models for explaining and preventing executive disaster. California Management Review, 2 (51), 170-193.

Fries, R., Chowdhury, M., Brummond, J. (2009). Transportation Infrastructure Security Utilizing Intelligent Transportation Systems. John Wiley \& Sons Inc.

Galor, W. (ed.) (2011). Carriage and securing of oversize cargo in transport. Szczecin: Maritime University of Szczecin. 
Genca, E., Duffieb, N., Reinharta, G. (2014), Event-Based Supply Chain Early Warning System for an Adaptive Production Control. Procedia CIRP, 19, 39-44.

Gleissner, H., Femerling, J.C. (2013). Logistics, Springer Texts in Business and Economics, Switzerland: Springer International Publishing.

Haji-Kazemi, S. (2015). The Early Warning Procedure in Projects. Foundations, Approaches and Challenges. Trondheim: Norwegian University of Science and Technology.

Hofstede, G. (1984). Culture's consequences: International differences in work-related values (2nd ed.). Beverly Hills, CA: SagePublications Ltd.

Klakegg, O.J., Williams, T., Walker, D., Andersen, B., Magnussen, O.M. (2010). Early Warning Signs in Complex Projects. Newtown Square, PA: Project Management Institute.

Lieb, K.J., Lieb, R.C. (2010). Environmental sustainability in the third-party logistics (3PL) industry. International Journal of Physical Distribution \& Logistics Management, 7 (40), 524-533.

Lovallo, D., Kahneman, D. (2003). Delusions of success: How optimism undermines executives' decisions. Harvard Business Review, July, 56-63.

Meyer, M.D. (2016). Transportation Planning Handbook. John Wiley \& Sons Inc.

Mir, F.A., Pinnington, A.H. (2014). Exploring the value of project management: Linking Project Management Performance and Project Success. International Journal of Project Management, 32, 202-217.

Nikander, I.O. (2002). Early warnings: A phenomenon in project management. Doctoral dissertation. Espoo, Finland: Helsinki University of Technology.

Pisz, I., Łapuńka, I. (2016). Transportation Services as Specific Logistics Projects for Oversized Cargo in Poland. In: M. Bąk (ed.), Transport Development Challenges in the Twenty-First Century: Proceedings of the 2015 TranSopot Conference, Springer Proceedings in Business and Economics (pp. 139-160), Springer.

Weintrit, A., Neumann, T. (eds.) (2013). Marine navigation and safety of sea transportation: STCW, maritime education and training (MET), human resources and crew manning, maritime policy, logistics and economics matters. London: Taylor \& Francis Group.

Wieland, A., Wallenburg, C.M. (2013). The influence of relational competencies on supply chain resilience: a relational view. International Journal of Physical Distribution \& Logistics Management, 4 (43), 300-320.

Wiktorowska-Jasik, A. (2016). Market of transport services - attempt at structural-functional identification. European Journal of Service Management, 2 (18), 55-61.

Williams, T.M. (2007). Post-project reviews to gain effective lessons learned. Newtown Square, PA: Project Management Institute.

Williams, T., Klakegg, O.J., Walker, D.H.T., Andersen, B., Magnussen, O.M. (2012). Identifying and acting on early warning signs in complex projects. Project Management Journal, 2 (43), 37-53.

Cite this article aS: Pisz, I. (2018). Recognizing early warning signs in transportation services. European Journal of Service Management, 2 (26), 185-192. DOI: 10.18276/ejsm.2018.26-23. 